\title{
IMPACTO DE FATORES METEOROLÓGICOS SOBRE AS CONCENTRAÇÕES DE OZÔNIO MODELADOS POR ANÁLISE DE SÉRIES TEMPORAIS E MÉTODOS ESTATÍSTICOS MULTIVARIADOS
}

\author{
A. SOUZA ${ }^{1}$, D. A. S. SANTOS ${ }^{2}$, F. ARISTONE ${ }^{1}$, E. KOVAČ-ANDRIĆ ${ }^{3}$, B. MATASOVIĆ ${ }^{3}$, J.C.PIRES ${ }^{4}$, P. V. IKEFUTI \\ ${ }^{1}$ Instituto de Física, Universidade Federal de Mato Grosso do Sul, ${ }^{2}$ Universidade Federal de Mato \\ Grosso; ${ }^{3}$ University of Osijek, Osijek Department of Chemistry Croacia, ${ }^{4}$ Universidade do Porto \\ amaury.de@uol.com.br ${ }^{*}$
}

Submetido 29/08/2016 - Aceito 04/08/2017

DOI: $10.15628 /$ holos.2017.5033

\section{RESUMO}

O objetivo é desenvolver um modelo para prever as concentrações de ozônio em função das variáveis climáticas. As medidas de concentração do ozônio foram realizadas na Universidade Federal de Mato Grosso do Sul, utilizando dados do período de janeiro a dezembro de 2014. As variáveis preditoras referentes ao clima (umidade relativa, velocidade do vento, chuva, aerossóis, índice de claridade, radiação solar global e temperatura do ar) foram cedidas pela CEMTEC-MS.
Foram realizadas análises de componentes principais (ACP) e análises de regressão linear múltipla (MLR). As relações observadas nestas análises foram usadas para obter uma equação de regressão que liga as concentrações de ozônio diurnas com parâmetros climáticos. O modelo desenvolvido é capaz de explicar 99\% da variabilidade nas concentrações de ozônio de superfície com um erro de $0,2 \%$.

PALAVRAS-CHAVE: ozônio urbano, Campo Grande, parâmetros meteorológicos.

\section{METEOROLOGICAL IMPACT FACTORS ON THE MODELING OF OZONE CONCENTRATIONS USING ANALYSIS OF TEMPORAL SERIES AND MULTIVARIATE STATISTIC METHODS}

\begin{abstract}
The objective is to develop a model to predict ozone concentrations due to climatic variables. The ozone concentration measurements were carried out at the Federal University of South Mato Grosso, using data from January to December 2014. The predictive variables for the climate (relative humidity, wind speed, rain, aerosols, clearness index, solar radiation and air temperature) were provided by CEMTEC-MS. Principal
\end{abstract}

component analysis (PCA) and analysis of multiple linear regression (MLR) have been carried out. The relationship observed in these analyzes were used to obtain a regression equation that links the daytime ozone concentrations with climate parameters. The model is able to explain $99 \%$ of the variability in surface ozone concentrations with a $0.2 \%$ error.

KEYWORDS: urban ozone, Campo Grande, meteorological parameters. 


\section{INTRODUÇÃO}

Com o desenvolvimento da economia e da rápida industrialização, a poluição do ar urbano tornou-se uma das questões mais importantes nos países em desenvolvimento. A distribuição temporal e espacial dos poluentes é determinada por condições meteorológicas, processos físicos e químicos na atmosfera, e nos processos de remoção de poluentes.

Poluentes atmosféricos têm efeitos adversos na saúde humana, nos ecossistemas e, ainda, estão associados com a mudança climática (Poschl, 2005; Pui, Chen \& Zuo, 2014). Nos países em desenvolvimento vivenciam uma elevada concentração desses poluentes devido ao rápido crescimento da população, da industrialização, do transporte e urbanização. As interações de multi escalas das condições meteorológicas afetam a qualidade do ar (Jiang, Dirks \& Luo, 2014). Em alguns casos, a poluição do ar é causada por condições climáticas desfavoráveis em vez do aumento abrupto das emissões (Cheng et al., 2007; Zheng et al., 2015) e a redução da emissão, nem sempre resultam na diminuição das concentrações de poluentes (Stoeckenius et al., 2015). Circulação de escala sinótica regula as condições meteorológicas locais e é eficaz para identificar o nível de poluição do ar (Oanh, Chutimon, Ekbordin, \& Supat, 2005). Sendo esse último, como o principal fator de condução das variações do dia-a-dia das concentrações de poluentes (Lee, Ballinger \& Domino, 2012).

A China começou a publicar os dados de concentração em tempo real dos poluentes, a partir das redes de monitoramento da qualidade do ar, após vários eventos de poluição graves em todo o país (Sun et al., 2014; Wang et al., 2014, Zheng et al., 2015). No Brasil, há também a divulgação desses dados através do INPE (Instituto Nacional de Pesquisas Espaciais), da USP (Laboratório de Poluição Atmosférica) e da CETESB (Companhia Ambiental de São Paulo). O PROCONVE (Programa de Controle da Poluição do Ar de Veículos Automotores) é um programa brasileiro que existe desde 1988, e que conseguiu reduzir as emissões dos gases, embora a frota de veículos tenha crescido consideravelmente desde os anos 1980. Alguns fatores, como melhoramentos tecnológicos realizados em veículos, associadas ao processo de combustão e uso de catalisadores, além de melhorias na qualidade do combustível, conseguiram compensar o grande aumento da frota de veículos em relação à emissão de poluentes atmosféricos.

Os processos físicos e químicos dos poluentes, também desempenham um papel importante na poluição do ar. Com uma elevada atividade química, o ozônio $\left(\mathrm{O}_{3}\right)$ é um dos poluentes secundários mais importantes, além de desempenhar um papel chave nas reações fotoquímicas na atmosfera. Ocasionalmente, a concentração desse gás medido em áreas rurais é ainda maior do que os medidos em grandes centros urbanos (Asaf et al., 2011). Compostos orgânicos voláteis (VOCs) têm atraído a atenção dos investigadores nos últimos anos, são precursores importantes para $\circ \mathrm{O}_{3}$, e que podem ser utilizados para avaliar o potencial de sua formação (Xu, Zhang, Xing \& Deng, 2015). Recentemente, pesquisas realizadas por He et al. (2016) revelam que o tráfego contribuiu com mais de 50\% de dióxido de azoto (NO2) em grandes cidades e sua contribuição, está intimamente relacionado com o transporte local e regional. A interação entre os $\mathrm{NO}_{2}$ e $\mathrm{O}_{3}$ é uma das questões complexas e o transporte desse último poluente é afetada pelo processo químico dessa ação (Asaf et al., 2011). 
Interações fotoquímicas de VOCs e o $\mathrm{NO} 2$ são associados com a produção de $\mathrm{O}_{3}$ ao nível da superfície. Além disso, a concentração temporal desse poluente é significativamente acompanhada das condições meteorológicas, incluindo a radiação solar, temperatura do ar, umidade relativa, precipitação e velocidade e direção do vento (Hastie et al., 1999; Kovač-Andrić, Brana \& Gvozdić, 2009). $\mathrm{O} \mathrm{O}_{3}$, no nível da superfície, tem efeitos negativos sobre a saúde humana, tais como dor de cabeça, irritação nos olhos, infecção respiratória e inflamação dos pulmões, bem como sobre a agricultura (Ashmore, 2005; Pinto, Blande, Souza, Amnerg \& Holopainen, 2010).

$\mathrm{O} \mathrm{O}_{3}$ mostra uma tendência crescente no Estado de Mato Grosso do Sul, desde 2004, e tem sido o principal poluente em muitas áreas dessa região (Souza, Kovač, Brunislav \& Markovi, 2016; Souza, Pavao \& Garcia, 2013; Souza, Aristones \& Goncalves, 2015; Souza, Aristones, Pavao \& Fernandes, 2014; Pires, Souza, Pavão \& Martins, 2014). O município de Campo Grande, localizado no centro desse Estado, está próximo de cidades com indústrias pesadas nas áreas químicas, refinaria, aço, de geração de energia como também, tem forte influência dos altos índices de queimadas realizadas para limpeza da terra para renovação de pastagens, o que resultou, e resulta, na péssima qualidade do ar na área de estudo. Compostos precursores do ozônio (VOCs, monóxido de carbono (CO) e NOx) à superfície, que tendem a acompanhar as condições meteorológicas, tornam o seu nível difícil de controlar (Tamerius, Wise, Uejio, Mccoy \& Comrie, 2007).

Sanchez-Ccoyllo, Ynoue, Martins \& Andrade (2006) descreveram o impacto de duas variáveis meteorológicas (velocidade do vento e temperatura do ar) na concentração e formação de $\mathrm{O}_{3}$, como também, nos hidrocarbonetos e nitrogênio (N). Nos resultados do modelo, propostos por esses autores, as concentrações de poluentes primários e concentrações de $\mathrm{O}_{3}$ estão em boa concordância com os dados medidos. Além disso, alterações na altura de mistura, velocidade do vento e dados de entrada de temperatura do ar, tem o maior efeito sobre o pico máximo desse gás. Os referidos autores estudaram também a frota de veículos na região metropolitana da cidade de São Paulo, com o modelo de qualidade do ar Eulerian, os quais contribuíram para a avaliação da melhoria da qualidade do ar e fornecer dados para uso na avaliação dos custos econômicos da implementação de um programa de controle de poluição automóvel, destinado a proteger a saúde humana.

Tentativas têm sido feitas para explicar a variabilidade nas concentrações de $\mathrm{O}_{3}$ pelo desenvolvimento de diferentes tipos de modelos estocásticos, determinísticos da escala local, regional e global (Chelani \& Devotta, 2006; Kim, 2010; Kumar \& Jain, 2010) e pelo modelo WRF (Weather Research and Forecasting) (Hu, Chen, Ying \& Zhang 2016). A análise fatorial de componentes principais foi aplicada para identificar as fontes de emissão e identificar os padrões de distribuição para os VOCs (Na, Kil-Choo \& Yong, 2005; Ohura, Amagai \& Fusaya, 2006; Duan, Tan, Yang, Wu \& Hao, 2008; You, Senthilselvan, Cherry, Kim \& Burstyn, 2008).

Partículas cujos tamanhos se encontram no intervalo igual ou superior a 0,05 $\mu \mathrm{m}$ e inferior a $1 \mu \mathrm{m}$, têm um tempo de permanência maior na atmosfera, sendo de aproximadamente de uma semana. Durante a permanência dessas partículas na atmosfera elas podem sofrer transformações por incorporação nas nuvens, condensação de vapores ou coagulação com partículas menores, além de apresentar o mesmo comprimento de onda da radiação solar incidente, provoca espalhamento dessa radiação. As partículas maiores (diâmetro >15 $\mu \mathrm{m}$ ) possuem um tempo de residência muito baixo na atmosfera, fazendo com que as mesmas se 
apresentem em baixas concentrações. Devido a esses motivos, a interação de partículas maiores com a radiação solar é menor quando comparada com as de menor tamanho. Entretanto, existem alguns casos especiais em que os efeitos de espalhamento da radiação solar podem ser acentuados, devido a essas partículas de aerossóis de grande diâmetro (Zheng et al., 2015).

O aumento da concentração de partículas de aerossóis tem efeito fundamental no balanço radiativo terrestre (Yamasoe, Artaxo, Miguel \& Allen, 2000; Holben, Schafer, Yamasoe \& Artaxo, 2002). Os aerossóis e as nuvens são componentes básicos no balanço energético terrestre, embora seu papel ainda esteja longe de ser compreendido e completamente quantificado. O chamado efeito direto dos aerossóis no clima consiste nos mecanismos que afetam diretamente o fluxo de radiação solar na superfície, podendo levar tanto ao aquecimento quanto ao resfriamento, dependendo das propriedades intrínsecas das partículas de aerossóis e da refletividade dessa superfície. O que ocorre é uma alteração no fluxo de energia solar, afetando o perfil de temperatura da atmosfera.

As principais fontes de partículas de aerossóis são: poeira do solo, sulfato (proveniente da oxidação do SO2), emissões de queimadas de florestas, dentre outros. Os aerossóis troposféricos afetam diretamente o balanço radiativo (absorção e espalhamento de radiação) e/ou indiretamente (influenciando nas propriedades radiativas de nuvens). As nuvens cobrem aproximadamente $60 \%$ da superfície terrestre e atuam no ciclo energético através de duas maneiras: as nuvens mais baixas e espessas refletem radiação solar de volta ao espaço e as nuvens mais altas e finas transmitem a radiação solar e ao mesmo tempo bloqueiam a passagem de radiação infravermelha emitida pela Terra.

A maior fonte de aerossóis para a atmosfera na América do Sul são as emissões por queimadas de florestas e cerrados, que ocorrem principalmente na estação seca na região Centro-Oeste (He et al., 2016). As florestas e os cerrados brasileiros são regiões onde, historicamente, ocorrem queima de biomassa em função do processo natural do uso do solo pelos agricultores e do uso da lenha como combustível, mas o número de queimadas tem aumentado significativamente nos últimos anos. Observando-se a variação sazonal da concentração de $\mathrm{O}_{3}$ no ano, em Campo Grande, Mato Grosso do Sul, notou-se que este foi significativamente mais alta durante os meses de agosto e setembro, final do período seco.

As maiores concentrações ocorrem, coincidentes, para os meses nos quais a queima de biomassa é mais intensa, associada aos baixos índices pluviométricos. No entanto, o mesmo padrão é observado para a radiação solar global, extraterrestre e índice de ultravioleta e índice de limpidez. Há uma diferença significativa das concentrações de $\mathrm{O}_{3}$ entre os meses secos e os meses chuvosos. Apesar dos eventos de chuvas serem mais efetivos na remoção do material particulado, de um modo geral, esse comportamento não é observado em Campo Grande, com o índice de limpidez e a concentração de 03. Conforme o que foi exposto, o objetivo do estudo é determinar como a concentração de $\mathrm{O}_{3}$ depende das variáveis climáticas.

\section{METODOLOGIA}

Para a presente pesquisa, utilizaram-se dados de temperatura e umidade relativa do ar e precipitação pluviométrica, concentração de ozônio $\left(\mathrm{O}_{3}\right)$ e monóxido de carbono (CO), velocidade 
dos ventos, aerossóis, índice de claridade e radiação solar, da cidade de Campo Grande (MS), fornecidos pelo Centro de Monitoramento de Clima e Recursos Hídricos de Mato Grosso do Sul (CEMTEC) cujas coordenadas geográficas são: $20^{\circ} 27^{\prime} \mathrm{S}, 54^{\circ} 37^{\prime} \mathrm{W}, 530 \mathrm{~m}$ de alt. $\mathrm{O}$ período de estudo ocorreu de janeiro a dezembro de 2014, com 359 dias, e teve como padrão de qualidade do ar de 81,2 ppb, seguindo a Resolução do CONAMA ( $n-003 / 2008$ ). De acordo com a climatologia local, o período de abril a outubro abrange a estação seca e nos meses de outubro a março compreendem a estação chuvosa, com período de transição nos meses de abril e outubro. (Souza, Fernades, Albrez \& Galvinio, 2012). Foram considerados como variável dependente (Y) a concentração de $\mathrm{O}_{3}$ e como variável independente $(X)$, os dias de estudo, temperatura do ar, chuva, umidade relativa do ar, velocidade dos ventos, radiação solar, índice de claridade e CO. A transformação da variável dia na variável ano-centralizada (ano menos o ponto médio do período de estudo) se fez necessária, já que em modelos de regressão polinomial, os termos da equação frequentemente são altamente correlacionados, e expressar a variável independente como um desvio de sua média reduz substancialmente à auto correlação entre eles. Praticou-se ainda, a análise de tendência da série histórica, utilizando um modelo de regressão linear múltipla que melhor descreveu a relação existente entre a variável independente $X$ e a variável dependente $Y$, segundo a equação: $Y=\beta_{0}+\beta_{1} X_{1}+\beta_{2} X_{2}+\cdots+\beta_{k} X_{k}+\varepsilon$, onde $k$ é o número de variáveis, $X_{j}$ são regressores, $\beta_{j}$ são os estimadores, e $\varepsilon$ é o erro padrão. Como medida de precisão, utilizou-se o coeficiente de determinação $\mathrm{R}^{2}$.

Os dados diários e adimensionais no comprimento de onda $0.55 \mu \mathrm{m}$ da espessura ótica de aerossóis foram coletadas pelo instrumento MODIS (Moderate Resolution Imaging Spectroradiometer) a bordo do satélite AQUA/NASA obtidas do Sistema de Informações Ambientais da Divisão de Satélites Ambientais do Centro de Previsão de Tempo e Estudos Climáticos (INPE/CPTEC/SISAM).

O índice de claridade $\left(k_{t}\right)$ determina a cobertura do céu, definido como a razão entre a radiação solar incidente $\left(R_{g}\right)$ e a radiação no topo da atmosfera $\left(R_{o}\right)$ (ambos em MJ m $\mathrm{dia}^{-1}$ ) que foi estimada pela Equação 2:

$$
\begin{gathered}
\mathrm{K}_{\mathrm{t}}=\frac{\mathrm{R}_{\mathrm{g}}}{\mathrm{R}_{0}} \\
R_{0}=\frac{24(60) G_{s c} \cdot D}{\pi} \cdot\left\{W_{s} \cdot \sin (\rho) \cdot \sin (\delta)+\cos (\delta) \cdot \sin \left(W_{s}\right)\right\}
\end{gathered}
$$

sendo $R_{O}$ : radiação extraterrestre ( $\left.\mathrm{MJ} \mathrm{m} \mathrm{m}^{-2} \mathrm{dia}^{-1}\right) ; G_{s c}$ : constante solar=0,0820 ( $\left.\mathrm{MJ} \mathrm{m}^{-2} \mathrm{dia}^{-1}\right) ; D$ : declinação solar (radianos); e $W_{s}$ : ângulo horário do por do sol (radianos)

Esse índice foi determinado pelo tipo de cobertura do céu de acordo com a metodologia proposta de Ricieri (1998), em que no intervalo de $0<K_{\mathrm{t}}<0.3$, indicam que as radiações globais e difusas são praticamente iguais e a radiação direta está próxima de zero, classificando o céu nessas condições como nublado. Para $0.3 \leq \mathrm{K}_{\mathrm{t}} \leq 0.65$, as radiações, difusa e direta, mantêm-se próximas denominando de céu parcialmente nublado. E entre $0.65<K_{\mathrm{t}}<1$, a radiação direta se aproxima da global, enquanto a difusa tende ao mínimo nessas condições, dessa feita, denominou-se de céu limpo. 
Neste estudo, equação de regressão linear múltipla (MLR) e analise de componentes principais (ACP) foram combinados para executar a análise de regressão principal (PCR). Este modelo PCR foi adotado para estimar a concentração de $\mathrm{O}_{3}$.

Análise de componentes principais transforma o conjunto de dados original de $\mathrm{n}$ variáveis, que são correlacionados entre si, em vários graus para um novo conjunto de dados, que contém n número de componentes principais não correlacionadas (PCs). Os PCs são funções lineares das variáveis originais, de modo que a soma dos desvios são iguais as variáveis originais e novas, as quais são sequenciadas a partir da maior para a menor variância. O primeiro PC explica a maior quantidade de variância dos dados. A próxima maior variância é explicada pelo segundo PC e assim por diante, para todos os $\mathrm{n}$ PCs. Os valores de todos os PCs podem ser obtido pela mesma equação, como as Equações 2 e 3. Essas duas equações são para um PC1 e PC 2. Embora o número de PCs e variáveis originais são iguais, normalmente a maior parte da variância do conjunto de dados pode ser explicada pelos primeiros PCs, e que podem ser usados para representar as observações originais (Abdul-Waheb, Bakheit \& Al-Alawi , 2005; Olsen, Chappell \& Loftis, 2012). Isto ajuda a reduzir a dimensionalidade do conjunto de dados original.

$$
\begin{aligned}
& P C_{1}=a_{11} x_{1}+a_{12} x_{2}+\cdots+a_{1 n} x_{n}=\sum_{j=1}^{n} a_{1 j} x_{j} \\
& P C_{2}=a_{21} x_{1}+a_{22} x_{2}+\cdots+a_{2 n} x_{n}=\sum_{j=1}^{n} a_{2 j} x_{j}
\end{aligned}
$$

em que $x_{1}, x_{2}, \ldots, x_{n}$ são as variáveis originais no conjunto de dados e $a_{i j}$ são os vetores próprios.

Os valores próprios são as variâncias dos PCs e os coeficientes $a_{i j}$ são os vetores próprios extraídos da covariância ou de correlação matriz do conjunto de dados. Os valores próprios da matriz de dados podem ser calculados pela Equação 5 como mostrado abaixo:

$$
|C-\lambda I|=0
$$

o qual $C$ é a matriz de correlação / covariância, $\lambda$ é o valor próprio e $I$ é a matriz identidade. Os coeficientes, ou os pesos das variáveis no PC, são calculados pela Equação 6:

$$
|C-\lambda I| a_{j j}=0
$$

Devido às diferenças nas unidades das variáveis de demanda de energia utilizadas neste estudo, uma matriz de correlação das variáveis foi usada para obter valores e vetores próprios. Esses vetores, multiplicados pela raiz quadrada dos valores próprios, produzem uma matriz de coeficientes $n \times n$, que são chamadas cargas variáveis. A importância de cada variável original para um determinado PC é representada por essas cargas. Além disso, a soma dos produtos das cargas variáveis e os valores das variáveis originais produz um novo conjunto de valores de dados, que são chamadas de pontuação dos componentes. Esses resultados podem ser utilizados 
em várias equações lineares, como novas variáveis para realizar prognóstico da demanda de energia.

A equação geral de um modelo MLR pode ser expressa como abaixo (Montgomery, Peck \& Vining, 2001):

$$
y=a_{0}+a_{1} x_{1}+a_{2} x_{2}+\cdots+a_{n} x_{n}
$$

sendo ya variável dependente, $a_{i}$ e $x_{i}(i=0,1, \ldots, n)$ são geralmente os parâmetros estimados pelo método dos mínimos quadrados, e as variáveis independentes, respectivamente.

$\mathrm{Na}$ análise, os valores de PCR, MLR e PCA são combinados em conjunto para estabelecer uma relação entre a variável dependente e os PCs selecionados das variáveis de entrada (Pires et al., 2014). Os componentes principais obtidos a partir do ACP são tomados como a variável independente na equação de regressão linear múltipla, para realizar a análise de PCR. A equação geral de modelo de PCR é expressa da seguinte maneira:

$$
y=a_{1} \cdot P C_{1}+a_{2} \cdot P C_{2}+\cdots+a_{n} \cdot P C_{n}
$$

Optou-se por modelar usando apenas os índices de $\mathrm{CP}_{1}$ até $\mathrm{CP}_{6}$, devido à existência da correlação entre esses índices e estas variáveis. Iniciou-se a modelagem múltipla colocando o $\mathrm{O}_{3}$ em função das variáveis estudadas. O modelo com maior significância estatística, com o menor AIC (Akaike's Information Criterion) e que se mostrou mais eficiente na previsão da concentração de ozônio. Vale ressaltar que, quanto menor o valor do AIC melhor o modelo.

\section{RESULTADOS E DISCUSSÕES}

A concentração de ozônio $\left(\mathrm{O}_{3}\right)$ tem o seu pico máximo nos meses de julho a dezembro, da ordem de $52.8 \mathrm{ppb}$, enquanto que nos demais meses do ano de estudo, esses valores foram menores, atingindo mínimos de $0.7 \mathrm{ppb}$. Notou-se ainda, que a média e a mediana encontradas foram de 17.8 e 16.2 ppb, respectivamente (Tabela 1). Na tabela abaixo são apresentadas as variáveis meteorológicas como a chuva $(\mathrm{mm})$, Temperatura máxima do ar $\left({ }^{\circ} \mathrm{C}\right)$, umidade relativa do $\operatorname{ar}(\%)$, velocidade dos ventos $\left(\mathrm{m} \mathrm{s}^{-1}\right)$, radiação solar global $\left(\mathrm{W} \mathrm{m}^{-2}\right)$, aerossóis, índice de claridade e monóxido de carbono (ppb).

Tabela 1: Estatística descritiva das variáveis meteorológicas estudadas no período de estudo, de acordo com a média, desvio padrão (DP), coeficiente de variação (CV), mínimo e máximo.

\begin{tabular}{c|c|c|c|c|c|c|c|c|c}
\hline & $\begin{array}{c}\mathrm{T}_{\text {máx }} \\
\left({ }^{\circ} \mathrm{C}\right)\end{array}$ & $\begin{array}{c}\text { UR } \\
(\%)\end{array}$ & $\begin{array}{c}\text { Chuva } \\
(\mathrm{mm})\end{array}$ & $\begin{array}{c}\mathrm{VV} \\
\left(\mathrm{m} \mathrm{s}^{-1}\right)\end{array}$ & $\begin{array}{c}\mathrm{O}_{3} \\
(\mathrm{ppb})\end{array}$ & $\begin{array}{c}\mathrm{Rg} \\
\left(\mathrm{W} \mathrm{m}^{-2}\right)\end{array}$ & AOT $_{500}$ & $\mathrm{Kt}$ & $\begin{array}{c}\mathrm{CO} \\
(\mathrm{ppb})\end{array}$ \\
\hline Média & 29.9 & 65.5 & 3.6 & 5.95 & 17.8 & 5654.7 & 0.44 & 0.51 & 88.83 \\
D.P & 3.76 & 3.59 & 6.12 & 8.14 & 8.7 & 1614.1 & 0.20 & 0.03 & 18.11 \\
C.V & 22.08 & 12.02 & 28.55 & 228.29 & 28.55 & 28.54 & 46.79 & 6.73 & 20.38 \\
Mínimo & 15.2 & 26.5 & 0 & 2.4 & 0.7 & 600.80 & 0.01 & 0.37 & 41.94 \\
Máximo & 38.3 & 94.9 & 50 & 11.1 & 52.8 & 9198.40 & 1.05 & 0.57 & 139.59 \\
$\mathrm{~N}$ & 359 & 359 & 359 & 359 & 359 & 359 & 359 & 359 & 359 \\
\hline
\end{tabular}

Conforme mostra a Figura 1, pode-se verificar que a concentração de $\mathrm{O}_{3}$ apresentou o seguinte comportamento: valores máximos durante o dia, atingindo o seu valor máximo às $11 \mathrm{~h}$ 
(49,00 ppb), e mínimos durante a noite se estendendo pela madrugada (1,00 ppb, aproximadamente), no qual indicou médias em torno de 17,38 $\pm 5,32 \mathrm{ppb}$. Essa concentração média pode variar muito de um dia para outro, pois, essas variações diárias dependem unicamente das condições meteorológicas, tais como, presença de nuvens, radiação solar, precipitação e vento (Souza, Aristone, Pavao, Kofanovski \& Santos, 2015). Ilustrou-se na Figura 2 (A), a média mensal da concentração de $\mathrm{O}_{3}$. Observou-se que a falta de regularidade ou de linearidade, está relacionada as condições climáticas. Sabe-se que em dias mais ensolarados, a concentração de $\mathrm{O}_{3}$ é maior, porque quanto mais radiação solar passa pela atmosfera, maiores serão as reações fotoquímicas para a formação desse gás.

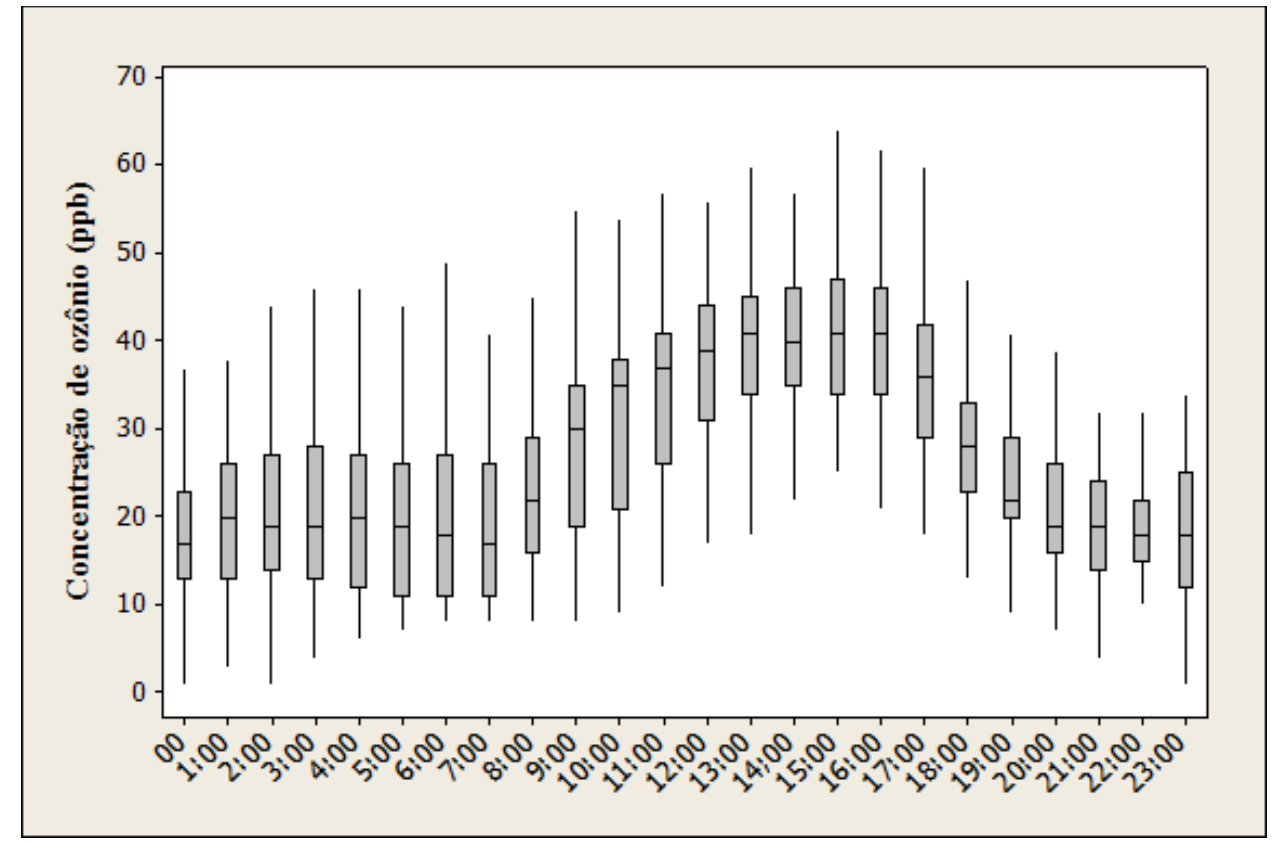

Figura 1: Média da Concentração horária de ozônio para a cidade de Campo Grande-MS.

Em uma visão geral, observou-se que as maiores concentrações médias de $\mathrm{O}_{3}$ ocorrem nos meses de julho a setembro. Viu-se ainda que, nos meses de julho a outubro, as concentrações médias dobram (ver Figura 2A), justamente no período em que ocorrem as queimadas na região. Ao analisar a velocidade e a direção dos ventos, percebeu-se também que exercem influência na concentração de $\mathrm{O}_{3}$, pois este leva espécies químicas de uma região para outra, assim, regiões que não poluem, também podem apresentar altas concentrações desse poluente (Souza et al., 2015). 


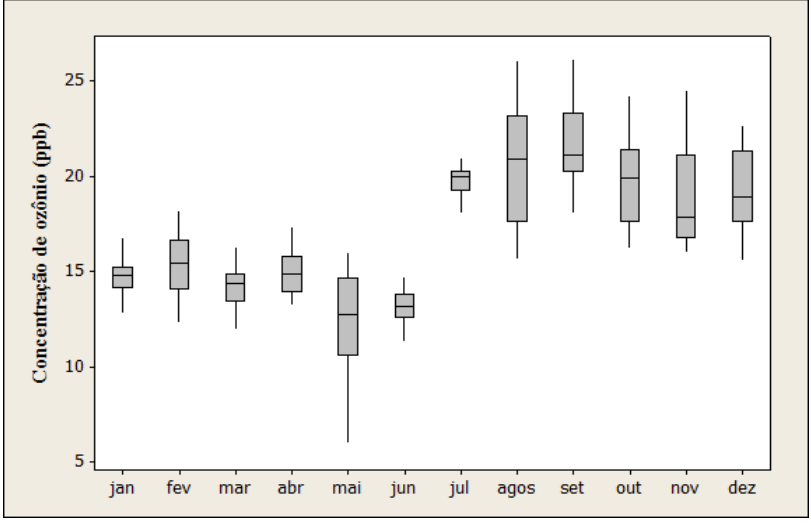

(a)

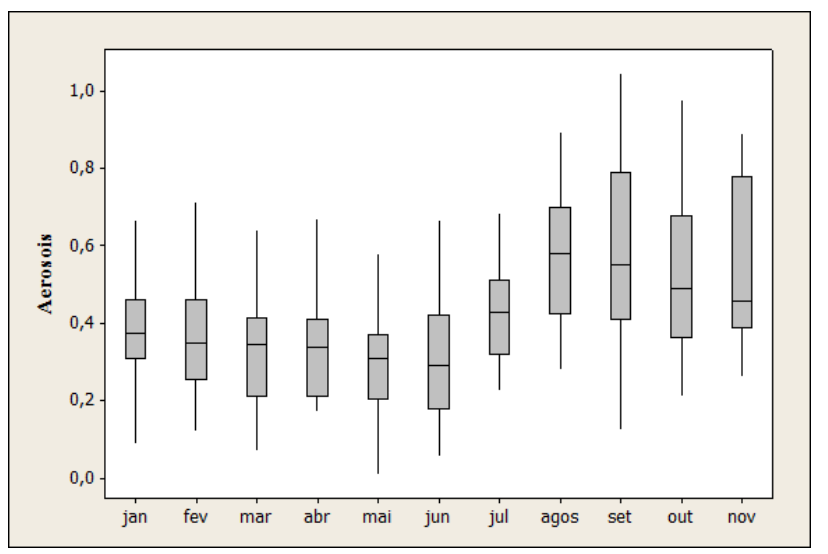

(b)

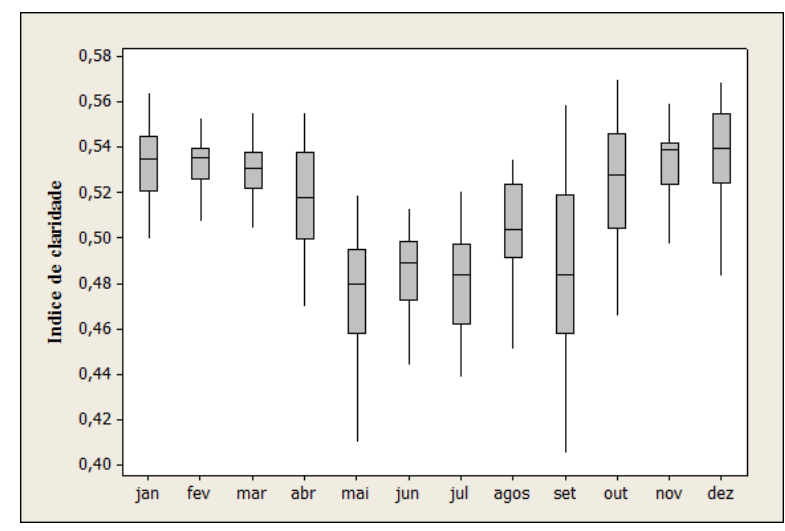

(e)

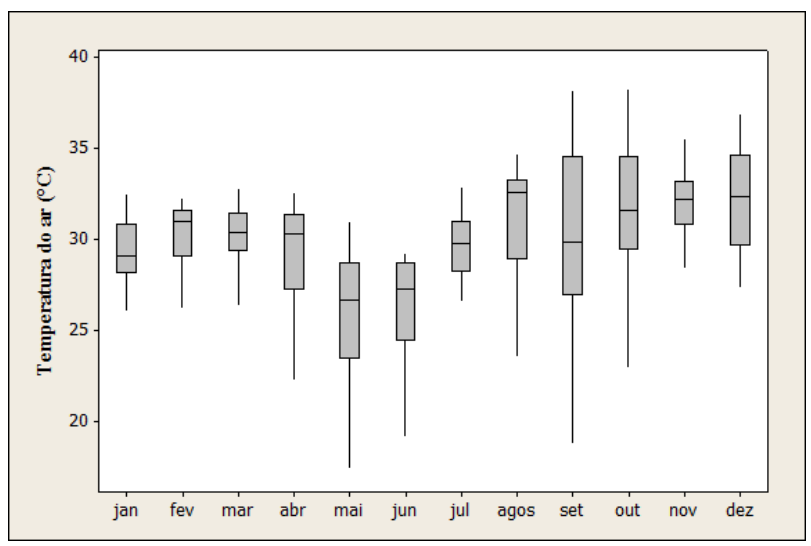

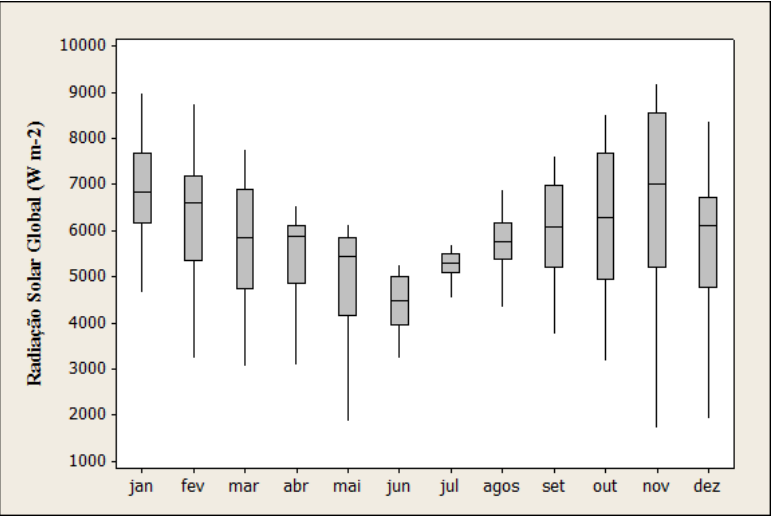

(b)

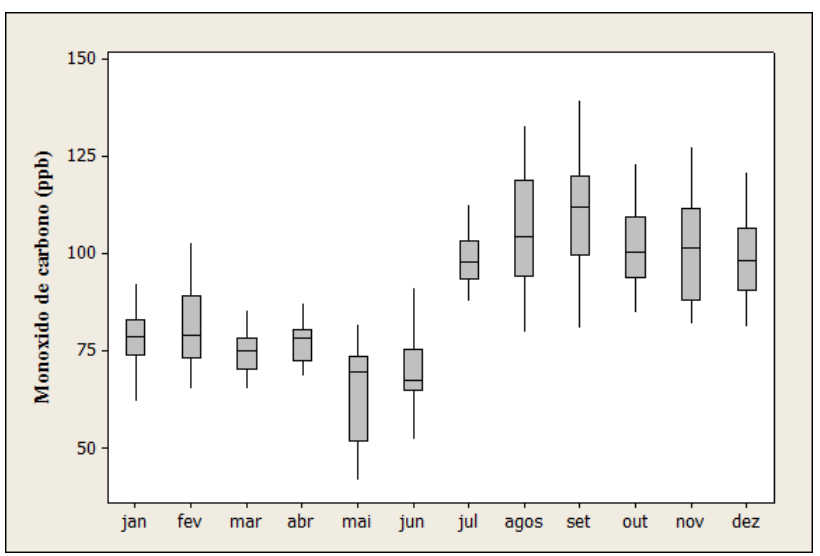

(d)

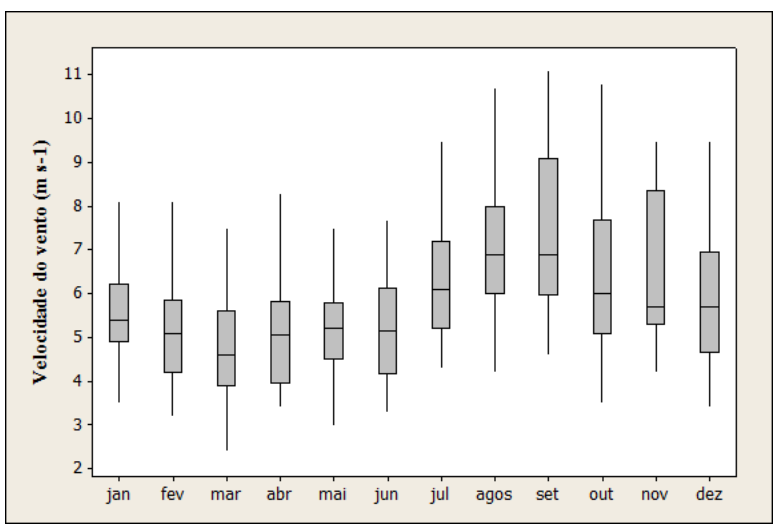

(f)

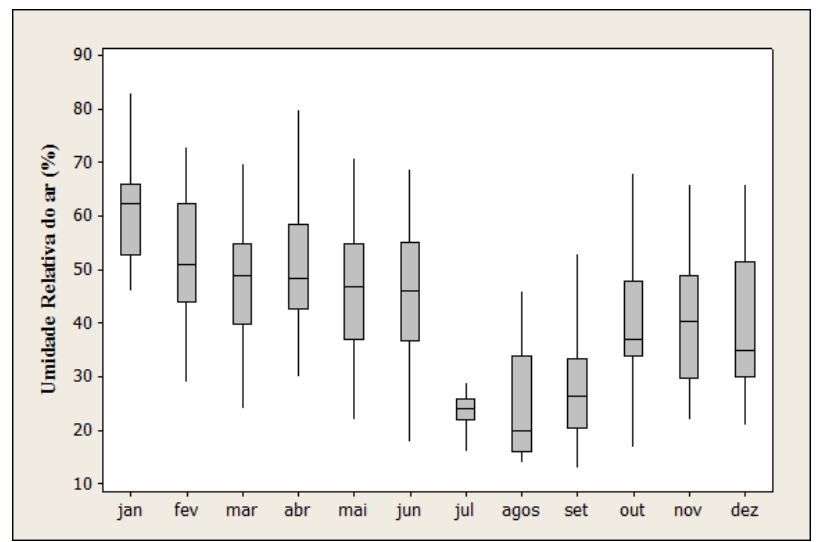


(g)

(h)

Figura 2: Boxplot da variabilidade do: concentração do ozonio (a), radiação solar global (b), aerossóis (OAD), (c), monóxido de carbono (ppb) (d), índice de claridade (e), Velocidade do vento (f), temperatura do ar $\left({ }^{\circ} \mathrm{C}\right)(\mathrm{g})$ e umidade relativa (\%) (h).

Os aerossóis exercem uma influência na $R_{g}$, em razão da sua maior presença em setembro, apontada pela Figura 2C, a qual indica que os aerossóis atmosféricos proporcionam redução de sua incidência nos horários de máxima intensidade (12 horas), devido as queimadas que ocorrem nesse mês.

O índice de limpidez (kt) atmosférico variou de 0,36 a 0,58 com uma média de 0,51. (Figura 2E). A distribuição de frequências evidencia a maior ocorrência de valores do Kt, entre o intervalo já citado. De acordo com Kudish e lanetz (1992), Kt acima de 0,60 pode ser representativo de dias claros. Isto significa que, para a cidade estudada - Campo Grande, os dias apresentaram valores de kt abaixo de 0,60, que corresponde a $40 \%$ dos dias estudados. Dias completamente nublados, algumas vezes com chuvas, são caracterizados por índice de claridade pequeno, entre 0,01 e 0,30, com frequências ocorrendo entre 1 e 4 ocorrências. Para valores intermediários, entre 0,31 e 0,60, a frequência variou no intervalo de 1 a 52 ocorrências, cujos dias podem ser classificados como parcialmente nublados.

O método da ACP gerou novas variáveis chamadas componentes principais, ortogonais ou não correlacionadas, seguida das correlações das variáveis e variação captada em cada componente resultante. A primeira componente principal (CP1) representa as variáveis de temperatura do ar $(0,831)$, a radiação solar global $(0,986)$ e velocidade do vento $(0,777)$, as quais contribuíram de forma positiva. A maior correlação na segunda componente (CP2) representa o índice de claridade $(0,982)$ e aerossóis $(0,953)$, na CP3 o ozônio $(0,962)$ e CO $(0,736)$, na CP4 a umidade relativa do ar $(-0,913)$ e na CP5 a chuva $(-0,977)$. Estas cinco componentes acumulam $89,9 \%$ da oscilação total das variáveis. Os valores estão destacados na Tabela 2. 
Tabela 2: Matriz da componente rotacionada da concentração de ozônio em Campo Grande, extração ACP, e rotação varimax, com normalização de Kaiser.

\begin{tabular}{l|c|c|c|c|c|c|c}
\hline VARIÁVEL & $\mathrm{CP}_{1}$ & $\mathrm{CP}_{2}$ & $\mathrm{CP}_{3}$ & $\mathrm{CP}_{4}$ & $\mathrm{CP}_{5}$ & $\mathrm{CP}_{6}$ & $\mathrm{CP}_{7}$ \\
\hline Ozônio & 0,202 & 0,060 & $-\mathbf{0 , 9 6 2}$ & 0,172 & 0,012 & $-0,021$ & 0,017 \\
TMAX & $\mathbf{0 , 8 3 1}$ & 0,101 & $-0,229$ & 0,452 & 0,079 & $-0,095$ & $-0,165$ \\
UR & $-0,131$ & $-0,101$ & 0,274 & $-\mathbf{0 , 9 1 3}$ & $-0,248$ & $-0,049$ & $-0,003$ \\
Chuva & 0,074 & 0,012 & 0,008 & $-0,193$ & $-\mathbf{0 , 9 7 7}$ & $-0,042$ & 0,003 \\
VV & $\mathbf{0 , 7 7 7}$ & $-0,101$ & $-0,174$ & 0,031 & $-0,043$ & 0,033 & 0,013 \\
Rg & $\mathbf{0 , 9 8 6}$ & 0,159 & $-0,024$ & $-0,029$ & $-0,041$ & $-0,024$ & $-0,001$ \\
AOT & 0,174 & $\mathbf{0 , 9 5 3}$ & $-0,215$ & 0,109 & $-0,051$ & $-0,003$ & $-0,015$ \\
Kt & 0,014 & $\mathbf{0 , 9 8 2}$ & $-0,019$ & $-0,079$ & $-0,057$ & $-0,136$ & 0,082 \\
CO & 0,572 & 0,215 & $-\mathbf{0 , 7 3 6}$ & 0,282 & 0,005 & $-0,022$ & $-0,067$ \\
\hline Variância & 3,248 & 1,842 & 1,656 & 1,210 & 1,034 & 1,004 & 0,005 \\
\% Var & 0,325 & 0,184 & 0,166 & 0,121 & 0,103 & 0,100 & 0,001 \\
\hline
\end{tabular}

Ao realizar a regressão multivariada, produziu-se um excelente coeficiente de determinação $(R=0,99)$, através da análise da linha de tendência, com um erro percentual de 0,2\%. De acordo com os resultados dos índices estatísticos, notou-se que os valores estimados da concentração do $\mathrm{O}_{3}$, utilizando o modelo, estão de acordo com os valores observados. A Figura 3b mostra os valores estimados desse gás durante os últimos 90 dias do ano de 2014, no período de 01 de outubro a 31 de dezembro.

Tabela 3: Resultado da analise de regressão para o modelo com os valores de intercepto (constante), temperatura, umidade do ar, chuva, velocidade dos ventos, radiação solar, índice de claridade e monóxido de carbono.

\begin{tabular}{l|c|c|c|c}
\hline PREDITOR & Coef & SE & T & P \\
\hline CONSTANTE & 19,171 & 2,762 & 6,940 & 0 \\
TMAX & $-0,9266$ & 0,0392 & $-23,630$ & 0 \\
UMIN & $-0,0178$ & 0,0019 & $-9,500$ & 0 \\
Chuva & $-0,0192$ & 0,0023 & $-8,340$ & 0 \\
VV & $-3,1824$ & 0,351 & $-9,080$ & 0 \\
Rg & $-0,00000138$ & 0,00000768 & $-0,180$ & 0 \\
AOT_500 & 14,306 & 3,071 & 4,660 & 0 \\
Kt & 16,595 & 2,11 & 7,860 & 0 \\
CO & 0,3441 & 0,0013 & 257,390 & 0 \\
\hline
\end{tabular}




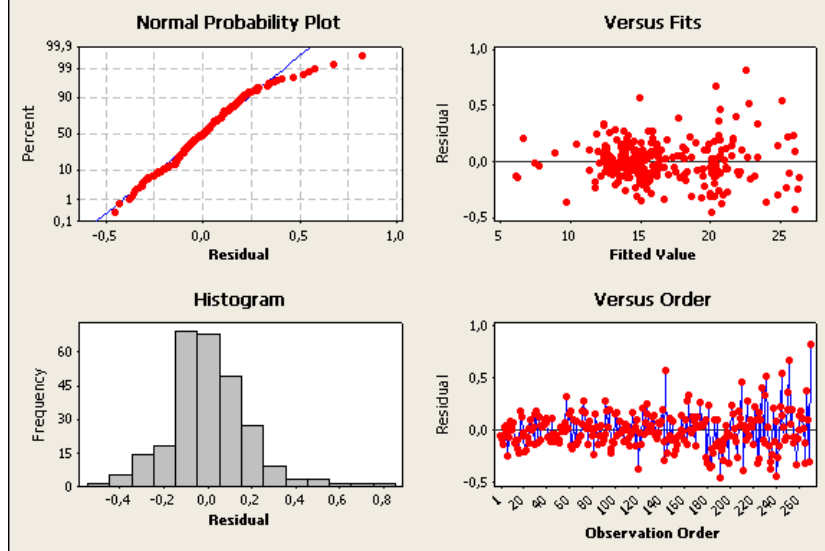

(a)

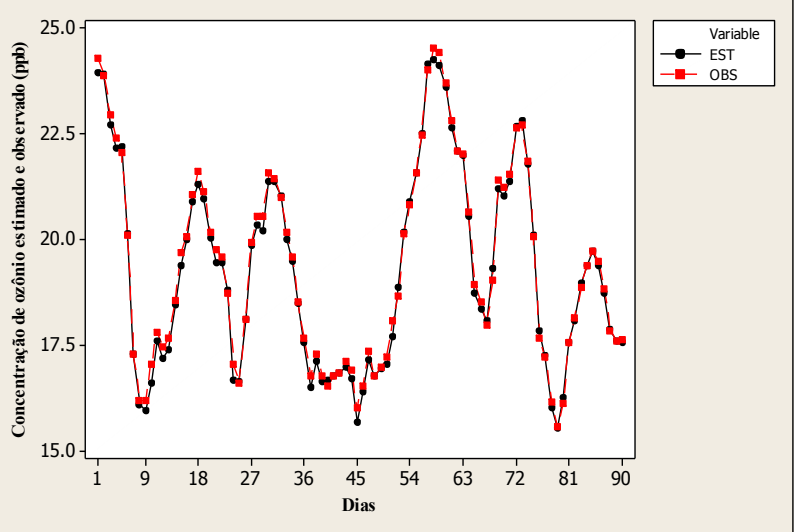

(b)

Figura 3: 3a) Desvios residuais e valores observados em função dos valores ajustados, histograma da variável resposta para o modelo de ajuste do ozônio em função dos anos estudados. 3b) Valores do ozônio observados e estimados pelo modelo, dias testados nos 90 dias em Campo Grande.

\section{CONCLUSÃO}

As regressões lineares revelam que as maiores concentrações de ozônio tendem a ocorrer em dias com maiores temperaturas do ar e maiores incidência da radiação solar, como também, com o adendo da magnitude dos ventos, os quais contribuem com $38,2 \%$ da variação desse acúmulo.

\section{REFERÊNCIAS}

Abdul-Wahab SA, Bakheit, CS, Al-Alawi SM (2005). Principal component and multiple regression analysis in modelling of ground-level ozone and factors affecting its concentrations, Environmental Modelling \& Software, 20(10), 1263-1271.

Asaf, D., Mordechai, P., Jihad, A., Aiman, S., Valeri, M., Eran, T., Allan, G., Menachem, L. (2011).Trans-boundary transport of ozone from the Eastern Mediterranean Coast. Atmospheric Environment, 45(31), 5595-5601.

Ashmore, M.R. Assessing the future global impacts of ozone on vegetation. (2005). Plant Cell and Environment, 56(8): $949-964$.

.Brasil. Resolução CONAMA $\mathrm{n}^{\circ} 3$, de 28 de junho de 1990.Disponivel em: http://www.mma.gov.br/port/conama/legiabre.cfm?codlegi=100

Chelani, A. B., Devotta, S. (2006). Air quality forecasting using a hybrid autoregressive and nonlinear model. Atmospheric Environment, 40(10), 1774-1780.

Cheng, C.S., Campbell, M., Li, Q., Auld, H., Day, N., Pengelly, D., Gingrich, S., Yap, D. (2007). A Synoptic Climatological Approach to Assess Climatic Impact on Air Quality in South-central Canada. Water Air Soil Pollut, 182(1), 117-130. 
Duan, J., Tan, J., Yang, L., Wu S.S., Hao, J. (2008). Concentration, sources and ozone formation potential of volatile organic compounds (VOCs) during ozone episode in Beijing. Atmospheric Research, 88(1), 25-35.

Hastie, D.R., Narayan, J., Schiller, C., Niki, H., Shepson, P.B., Sills, D.M.L.,Taylor, P.A. et al. (1999). Observational evidence for the impact of the lake breeze circulation on ozone concentrations in Southern Ontario. Atmospheric Environment, 33(2), 323-335.

He, J.J., Yu,Y., Xie, Y.C., Mao, H.J., Wu, L., Liu, N., Zhao, S.P. (2016). Numerical model-based artificial neural network model and its application for quantifying impact factors of urban air quality. Water, Air \& Soil Pollution, 227-235.

Holben, J.S., Schafer, B.N.E., Yamasoe, T.F., Artaxo, P. (2002). Atmospheric effects on insolation in the Brazilian Amazon: Observed modification of solar radiation by clouds and smoke and derived single scattering albedo of fire aerosols. Journal of Geophysical Research, 107(D20), 8074.

Hu, J., Chen, J., Ying, Q., Zhang, H. (2016). One-Year Simulation of Ozone and Particulate Matter in China Using WRF/CMAQ Modeling System. Atmos. Chem. Phys. Discuss, 16, 1-31.

Jiang, N., Dirks, K.N., Luo, K. (2014). Effects of local, synoptic and large-scale climate conditions on daily nitrogen dioxide concentrations in Auckland, New Zealand. Int. J. Climatol., 34, 1883-1897.[

Kim, S.E. (2010). Tree-based threshold modeling for short-term forecast of daily maximum ozone level. Stochastic Environmental Research and Risk Assessment, 24(1), 19-28.

Kovač-Andrić, E., Brana, J., Gvozdić, V. (2009). Impact of meteorological factors on ozone concentrations modelled by time series analysis and multivariate statistical methods. Ecological Informatics, 4, 117-122.

Kudish, A.I., lanetz, A. (1992). Analysis of the solar radiation data for Beer Sheva, Israel, and its environs. Solar Energy, 48(2), 97-106.

Kumar, U., Jain, V.K. (2010). ARIMA forecasting of ambient air pollutants $\left(\mathrm{O}_{3}, \mathrm{NO}, \mathrm{NO}_{2}\right.$ and $\left.\mathrm{CO}\right)$. Stochastic Environmental Research and Risk Assessment, 24(5), 751-760.

Lee, C.C., Ballinger, T.J., Domino, N.A. (2012). Utilizing Map Pattern Classification and Surface Weather Typing to Relate Climate to the Air Quality Index in Cleveland, Ohio. Atmospheric Environment, 63, 50-59.

Montogomery, D.C., Peck, E.A., Vining, G.G. (2001). Introduction to linear regression analysis. (3a ed.). New York, USA: John Wiley \& Sons.

$\mathrm{Na}$, K., Kil-Choo, M., Yong, P.K. (2005). Source contribution to aromatic VOC concentration and ozone formation potential in the atmosphere of Seoul. Atmospheric Environment, 39(30), 5517-5524.

Oanh, N.T.K., Chutimon, P., Ekbordin, W., Supat, W. (2005). Meteorological pattern classification and application for forecasting air pollution episode potential in a mountain-valley area. Atmospheric Environment, 39(7), 1211-1225.

Ohura, T., Amagai, T., Fusaya, M. (2006). Regional assessment of ambient volatile organic compounds in an industrial harbor area, Shizuoka, Japan. Atmospheric Environment, 40(2), 238-248. 
Olsen RL, Chappell RW, Loftis JC (2012). Water quality sample collection, data treatment and results presentation for principal components analysis-literature review and Illinois River watershed case study, Water Research, 46(9), 3110-3122.

Pinto, D.M., Blande, J.D., Souza, S.R., Amnerg, J., Holopainen, K. (2010). Plant volatile organic compounds (VOCs) in ozone $\left(\mathrm{O}_{3}\right)$ polluted atmospheres: the ecological effects. J Chem Ecol., $36(1), 22-34$.

Pires, J.C.M., Souza, A., Pavão, H.G., Martins, F.G. (2014). Variation of surface ozone in Campo Grande, Brazil: meteorological effect analysis and prediction. Environmental Science and Pollution Research International, 21, 10550-9.

Poschl, U. (2005). Atmospheric aerosols: Composition, transformation, climate and health effects. Angewandte Chemie-International Edition, 44(46), 7520-7540.

Pui, D.Y.H., Chen S.-C., Zuo, P. (2014). "PM2.5 in China: Measurements, sources, visibility and health effects, and mitigation". Particuology, 13, 1-26.

Ricieri, R.P. (1998). Modelos de estimativa e avaliação dos métodos de medida da radiação solar difusa. 1998. 81 f. Tese de doutorado em Energia na Agricultura. Universidade Estadual Paulista, Faculdade de Ciências Agronômicas, Botucatu, SP, Brasil.

Sanchez-Ccoyllo, O.R., Ynoue, R.Y., Martins, L.D., Andrade, M.F. (2006). Impacts of ozone precursor limitation and meteorological variables on ozone concentration in São Paulo, Brazil. Atmospheric Environment., 40, S552-S562, 2006.

Souza, A., Fernandes, W.A., Albrez, E.A., Galvinio, J.D. (2012). Analise de agrupamento da precipitação e da temperature no Mato Grosso do Sul.Acta Geografica, Boa Vista, v.6, n.12, 109-124.

Souza, A., Aristones, F., Pavao, H.G., Fernandes, W.A. (2014). Development of a Short-Term Ozone Prediction Tool in Campo Grande-MS-Brazil Area Based on Meteorological Variables. Open Journal of Air Pollution, 03, 42-51.

Souza, A., Aristones, F., Goncalves, F.V. (2015). Modeling of Surface and Weather Effects Ozone Concentration Using Neural Networks in West Center of Brazil. Journal of Climatology \& Weather Forecasting, 03(1), 4.

Souza, A., Aristone, F., Pavao, H.G., Kofanovski, A.Z., Santos, D.A.S. (2015). Impacto do ambiente atmosférico nas internações hospitalares por doenças respiratórias. Espacios, 36(24), 12.

Souza, A., Kovač, E., Brunislav, B., Markovi, B. (2016). Assessment of Ozone Variations and Meteorological Influences in West Center of Brazil, from 2004 to 2010. Water, Air and Soil Pollution (Print), 227, 313.

Souza, A., Pavao, H.G., Garcia, A.P. (2013). Modeling of ozone due to weather conditions. Revista Brasileira de Climatologia, 12, 7-21.

Stoeckenius, T.E., Christian, H., Justin, Z., Timothy, M.S., Benjamin, W., Tanarit, S. (2015). A comparison between 2010 and 2006 air quality and meteorological conditions, and emissions and boundary conditions used in simulations of the AQMEII-2 North American domain. Atmospheric Environment, 115, 389-403.

Sun, Y, Jiang, Q., Wang, Z., Fu, P., Li, J., Yang, T., Yin, Y. (2014). Investigation of the sources and evolution processes of severe haze pollution in Beijing in January 2013, J. Geophys. Res. Atmos., 119(7), 4380-4398. 
Tamerius, J., Wise, E., Uejio, C., Mccoy, A., Comrie, A.C. (2007). Climate and Human Health: Synthesizing Environmental Complexity and Uncertainty. Stochastic Environmental Research and Risk Assessment, 21(5), 601-613.

Xu, H., Zhang, H., Xing, Z.Y., Deng, J.J. (2015). Pollution characteristics and ozone formation potential of ambient VOCs in winter and spring in Xiamen. Environmental science, 36, 11-17.

Yamasoe, M.A., Artaxo, P., Miguel, A.H., Allen, A.G. (2000). Chemical composition of aerosol particles from direct emissions of biomass burning in the Amazon Basin: water-soluble species and trace elements. Atmospheric Environment, 34, 1641-1.653.

You, X., Senthilselvan, A., Cherry, N.M., Kim, H.G., Burstyn, I. (2008). Determinants of airborne concentrations of volatile organic compounds in rural areas of Western Canada. J Expo SciEnviron Epidemiol., 18(2), 117-28.

Wang, D., Hub, J., Xua, Y., Lva, D., Xiea, X., Kleemanb, M. et al. (2014). Source contributions to primary and secondary inorganic particulate matter during a severe wintertime PM2.5 pollution episode in Xi'an, China. Atmospheric Environment, 97, 182-194.

Zheng, B., Zhang, Q., Zhang, Y., He, K.B., Wang, G.J., Zheng, F.K., Duan, Y.L., Ma, Y.L., Kimoto, T. (2015). Heterogeneous chemistry: a mechanism missing in current models to explain secondary inorganic aerosol formation during the January 2013 haze episode in North China. Atmos. Chem. Phys., 15(4), 2031-2049. 